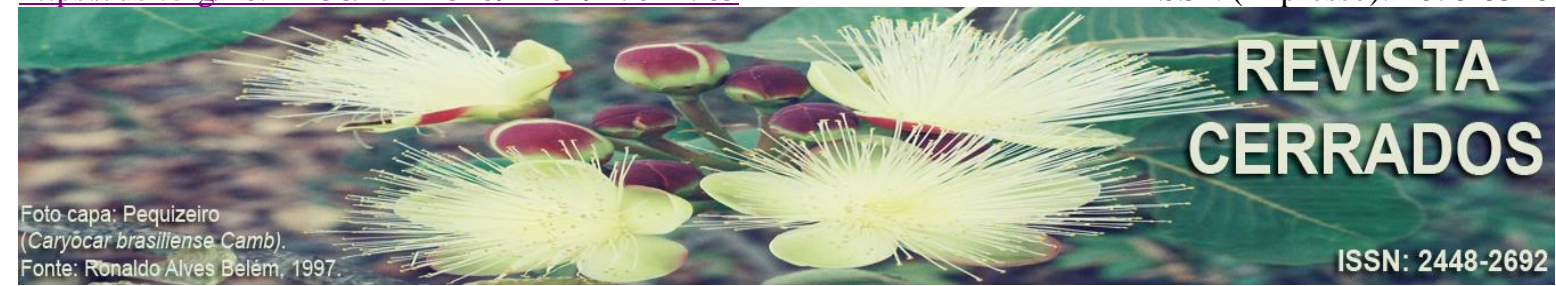

\title{
UMA LEITURA DO DOSSIÊ DA REVISTA BRASILEIRA DE EDUCAÇÃO EM GEOGRAFIA (2014): ora compêndios, ora livros escolares, ora livros didáticos
}

\section{A DOSSIER'S READING OF BRAZILIAN JOURNAL OF EDUCATION IN GEOGRAPHY (2014): however compendia, however schoolbooks, however textbooks}

\author{
UNE LECTURE DU DOSSIER DE LA REVUE BRÉSILIENNE \\ D'ÉDUCATION EN GÉOGRAPHIE (2014) : soit précis, soit manuels \\ scolaires, soit manuels didactiques
}

\author{
Bruno Falararo de Mello \\ Universidade Estadual Paulista Júlio de Mesquita Filho - UNESP \\ E-mail: <brunofmello@yahoo.com.br>. \\ João Pedro Pezzato \\ Universidade Estadual Paulista Júlio de Mesquita Filho - UNESP \\ E-mail: <jpezzato@rc.unesp.br>.
}

\begin{abstract}
RESUMO
O presente artigo tem por objetivo a análise de treze artigos publicados, em forma de um dossiê, na Revista Brasileira de Educação em Geografia vol. 4, n. 8, de 2014. Tal edição conta com vários autores de diversas universidades, tanto nacionais como internacionais, e trata de temas relativos à Geografia escolar e livros didáticos. A proposta deste artigo está inserida em um campo de pesquisa recente, contudo amplo, que estuda livros didáticos de Geografia. Na perspectiva da pesquisa documental, de caráter inventariante, todos os artigos foram inicialmente lidos. A leitura culminou com o mapeamento das instituições dos autores por estados, além de uma sistematização por meio de tabelas. Os artigos demonstram haver conexões entre os conteúdos dos livros didáticos e a história do pensamento geográfico. Nos próprios artigos podem ser notadas articulações das análises com a epistemologia da ciência de referência, a Geografia, mas de maneira e intensidade diferente cada qual. A principal convergência é quanto ao conceito de região, que é trabalhada em praticamente todos os livros didáticos. Os organizadores do dossiê tiveram o cuidado de apresentar ao debate acadêmico artigos que abordam matizes e reflexões diversas sobre autores e seus livros didáticos. Os livros didáticos são importantes elementos da cultura escolar. Eles se renovam a cada época em um movimento convergente ao das políticas educacionais. Como tema de pesquisa, o estudo do livro didático não se esgota: ele se renova a cada época.
\end{abstract}


MELLO, B. F.; PEZZATO, J. P.

Uma leitura do dossiê da Revista Brasileira de Educação em Geografia (2014): ora compêndios, ora livros escolares, ora livros didáticos

Palavras-chave: Ensino. Livro didático. Revista Brasileira de Educação em Geografia.

\begin{abstract}
This article aims at the analysis of thirteen articles published in the form of a dossier of textbooks in the Brazilian Journal of Education in Geography vol. 4, n. 8, 2014. This edition was co-written by several authors, both national and international, and from various universities. The purpose is the study of geography as school subject. From the perspective of documentary research, reading articles resulted in a mapping by States of the authors' institutions, and systematization by tables. The articles show that there are links between the content of textbooks and the history of geographical thought. This articles allow take connections between the analyzes with the epistemology of geography, but in a different and intensity each. The main convergence is on the concept of the region, which is designed in practically all manual. The organizers of the dossier have taken care to present articles in the academic debate with various nuances and reflections on the authors and their books. Textbooks are important elements of the school culture. They are renewed in every age, in a move to converge educational policies. As a research subject, textbook study does not end: it is renewed each time.
\end{abstract}

Keywords: Teaching. Textbook. Journal of Education in Geography.

\title{
RÉSUMÉ
}

Cet article vise à l'analyse de treize articles parus sous la forme d'un dossier de manuels scolaires chez Revue brésilienne d'éducation en géographie v. 4, n. 8, de 2014. Cette édition a été coécrite par plusieurs auteurs, à la fois nationaux et internationaux et issus de diverses universités. Il s'agit de sujets concernants à la géographie scolaire. Du point de vue de la recherche documentaire, la lecture des articles a abouti à une cartographie par états des institutions des auteurs, et une systématisation par tables. Les articles montrent qu'il y a des liens entre le contenu des manuels scolaires et l'histoire de la pensée géographique. Ces mêmes articles permettent de relever des connexions entre les analyses faites avec l'épistémologie de la géographie, mais de façon et d'intensité différente chacune. La convergence principale est sur le concept de la région, laquelle est conçue dans pratiquement tous les manuels. Les organisateurs du dossier ont pris du soin de présenter des articles de débat académiques qui traitent de diverses nuances et des réflexions sur des auteurs et leurs manuels. Les manuels scolaires sont des éléments importants de la culture scolaire. Ils se renouvellent en chaque époque, dans un mouvement convergent aux politiques éducatives. En tant que sujet de recherche, l'étude du manuel ne finit pas.

Mots-clés: Enseignement. Manuel scolaire. Revue brésilienne de l'éducation en géographie.

\section{INTRODUÇÃO}

A Revista Brasileira de Educação em Geografia se caracteriza por ser uma publicação científica independente. De formato exclusivamente eletrônico, que permite acesso Revista Cerrados, Montes Claros/MG, v.17, n. 2, p. 47-65, jul./dez.-2019. 
MELLO, B. F.; PEZZATO, J. P.

Uma leitura do dossiê da Revista Brasileira de Educação em Geografia (2014): ora compêndios, ora livros escolares, ora livros didáticos

gratuito, trata-se de uma forma democrática de divulgação do conhecimento. Conta com publicações semestrais, tendo a edição de lançamento em abril de 2011 na ocasião do XI Encontro Nacional de Prática de Ensino de Geografia promovido pelo ENPEG (Núcleo de Ensino de Pesquisa em Educação Geográfica) da Universidade Federal de Goiás - UFG, em Goiânia.

O periódico tem por objetivo publicar, disseminar e promover gratuitamente o intercâmbio nacional e internacional de pesquisas e prática educacionais ligadas à educação em Geografia em diferentes níveis de educação formal e não formal, valorizando os diferentes recortes temáticos e teórico-metodológicos de investigação.

Seu público alvo é variado: pesquisadores de nível superior, professorespesquisadores do nível básico e outros interessados sem vínculo formal que estejam, de certa forma, envolvidos com a educação. Considerando a importância que os livros didáticos possuem como instrumento substancial para o ensino-aprendizagem nas escolas, também se reconhece que nos últimos anos as pesquisas sobre eles têm ganhado grande impulso, conforme asseverado por Choppin:

Depois de ter sido negligenciada por longo tempo, as pesquisas históricas referentes aos livros didáticos e, posteriormente, as edições escolares, tiveram desde os anos 1960 e, sobretudo, nos últimos vinte anos, um considerável impulso (CHOPPIN, p. $551,2004)$.

Nosso objetivo é a proceder à análise de 13 artigos publicados em forma de um dossiê na Revista Brasileira de Educação em Geografia vol. 4, n. 8, de 2014, cujo tema são os livros didáticos de Geografia. Desse modo, buscamos evidenciar a importância dessas obras no ensino de Geografia no Brasil e, de forma mais ampla, sua importância para a cultura escolar.

\section{MATERIAL E MÉTODO: procedimentos para o estudo do estado de conhecimento}

A leitura e acurada análise dos artigos publicados em forma de dossiê na Revista Brasileira de Educação em Geografia, volume 4, número 8, 2014, edição dedicada à investigação da história da Geografia escolar, embasou a produção deste trabalho, cujo escopo é realizar o levantamento para análise da produção de livros didáticos de Geografia no Brasil. $\mathrm{Na}$ perspectiva da pesquisa documental, de caráter inventariante e descritiva, este artigo Revista Cerrados, Montes Claros/MG, v.17, n. 2, p. 47-65, jul./dez.-2019. 
MELLO, B. F.; PEZZATO, J. P.

Uma leitura do dossiê da Revista Brasileira de Educação em Geografia (2014): ora compêndios, ora livros escolares, ora livros didáticos

também objetiva fornecer algumas bases que permitam a reflexão a respeito do cenário das pesquisas do tema, bem como contribuir para pesquisas futuras sobre livros didáticos e ensino de Geografia.

Nesse sentido, as seguintes questões foram elaboradas: quais motivos levaram à publicação de um dossiê sobre o tema de livros didáticos na história da disciplina na Revista Brasileira de Educação em Geografia no ano de 2014? Tais produções estão, de alguma forma, ligadas com a realidade escolar nacional? As análises estabelecem relações com a história do pensamento geográfico e sua epistemologia?

A leitura inicial dos artigos foi feita com a intenção de apontar os principais pontos de discussão, a saber, quais elementos são comuns entre eles. Como análise de caráter individual, foi avaliado qual o foco/objetivo de cada um deles. A leitura feita deu ensejo, também, à elaboração do mapeamento desses artigos, de forma a espacializar essas produções (ou seja, onde foram produzidos).

\section{ANÁLISE DOS DADOS}

A melhor forma encontrada para apresentação e sistematização dos dados foi por meio de tabelas, gráficos e mapeamento. Em primeiro momento são feitas as apresentações dos artigos contidos no dossiê, principalmente dos seus autores e suas respectivas instituições, seguidos então pelo mapeamento das informações e suas respectivas análises.

O dossiê reúne treze artigos. Eles foram dispostos no Quadro 1, em que consta o título do artigo, nome(s) do(s) autor(es) e instituição a qual estão ligados. No Gráfico 1 o número de autores por instituições de ensino superior foi elencado, a fim de melhor visualização das informações.

Ao todo são dezoito autores, espalhados por oito universidades brasileiras e duas internacionais. Uma das autoras é uma integrante do corpo de professores de um colégio e outra é integrante de uma secretaria municipal de educação. Das instituições nacionais, cinco autores pertencem à Universidade de São Paulo (USP); na Universidade Federal do Triângulo Mineiro (UFTM), dois; na Universidade Estadual de Maringá (UEM), Universidade Federal de Goiás (UFG), Universidade Estadual do Rio Grande do Sul (UERGS), Universidade Federal da Paraíba (UFPB), Universidade Estadual Paulista (UNESP) e Universidade 
MELLO, B. F.; PEZZATO, J. P.

Uma leitura do dossiê da Revista Brasileira de Educação em Geografia (2014): ora compêndios, ora livros escolares, ora livros didáticos

Estadual de Alagoas (UNEAL), um autor cada qual. Já das universidades internacionais, dois autores pertencem à Universidade de Buenos Aires (UBA), e na Universidade de Lisboa há um autor.

Quadro 1 - Relação dos artigos publicados na Revista Brasileira de Educação em Geografia, volume 4, número 8 , de 2014

\begin{tabular}{|c|c|c|c|}
\hline Ordem & Título & Autor & $\begin{array}{c}\text { Instituição/ } \\
\text { Autor(es) }\end{array}$ \\
\hline 1 & $\begin{array}{l}\text { Apresentação do dossiê ora compêndios, ora livros } \\
\text { escolares, ora livros didáticos... sempre necessários } \\
\text { na Geografia escolar. }\end{array}$ & $\begin{array}{l}\text { Rosemberg Ferracini; } \\
\text { Veronica Hollman. }\end{array}$ & $\begin{array}{l}\text { USP (Universidade de São } \\
\text { Paulo) } \\
\text { UBA (Universidad de } \\
\text { Buenos Aires). }\end{array}$ \\
\hline 2 & O livro didático e o ensino de Geografia do Brasil & $\begin{array}{l}\text { Leonardo Dirceu de } \\
\text { Azambuja }\end{array}$ & $\begin{array}{l}\text { UEM (Universidade } \\
\text { Estadual de Maringá) }\end{array}$ \\
\hline 3 & $\begin{array}{l}\text { Os manuais escolares de Hermantina Riccioppo: } \\
\text { resgates da produção de conhecimento geográfico } \\
\text { escolar no Triângulo Mineiro, em meados do } \\
\text { século XX. }\end{array}$ & $\begin{array}{l}\text { Diego Carlos Pereira; } \\
\text { Amanda Regina } \\
\text { Gonçalves }\end{array}$ & $\begin{array}{l}\text { UFTM (Universidade } \\
\text { Federal do Triângulo } \\
\text { Mineiro); } \\
\text { UFTM; }\end{array}$ \\
\hline 4 & $\begin{array}{l}\text { Livros didáticos e o discurso do conhecimento } \\
\text { escolar em Geografia: a abordagem regional como } \\
\text { regularidade }\end{array}$ & Carolina Lima Vilela & Colégio Dom Pedro II \\
\hline 5 & $\begin{array}{l}\text { A produção e circulação do saber escolar: o } \\
\text { Nordeste enquanto conteúdo escolar nos livros } \\
\text { didáticos de Geografia }\end{array}$ & $\begin{array}{l}\text { Maria Ediney Ferreira } \\
\text { da Silva }\end{array}$ & $\begin{array}{l}\text { UNEAL (Universidade } \\
\text { Estadual de Alagoas) }\end{array}$ \\
\hline 6 & $\begin{array}{l}\text { Autores e livros didáticos regionais de Geografia } \\
(1870 \text { - 1910): elementos históricos e educacionais } \\
\text { para uma espacialização do fenômeno. }\end{array}$ & $\begin{array}{l}\text { Maria Deusia Lima } \\
\text { Angelo; } \\
\text { Maria Adailza Martins } \\
\text { de Albuquerque }\end{array}$ & $\begin{array}{c}\text { Secretaria Municipal de } \\
\text { Educação de João } \\
\text { Pessoa/PB e GPCES } \\
\text { (Grupo de Pesquisa } \\
\text { Ciências, Educação e } \\
\text { Sociedade) } \\
\text { UFPB (Universidade } \\
\text { Federal da Paraíba). }\end{array}$ \\
\hline 7 & $\begin{array}{l}\text { O Brasil é independente? Geografia e ideologia no } \\
\text { primeiro manual escolar do liberalismo português }\end{array}$ & Sérgio Claudino & Universidade de Lisboa \\
\hline 8 & $\begin{array}{l}\text { Aprendendo a ensinar através dos livros: notas } \\
\text { sobre a natureza e a produção dos manuais para } \\
\text { professores (Brasil e em Portugal - 1870-1970) }\end{array}$ & $\begin{array}{l}\text { Vivian Batista da } \\
\text { Silva; Rita de Cassia } \\
\text { Gallego; Paula Perin } \\
\text { Vicentini }\end{array}$ & $\begin{array}{l}\text { USP; } \\
\text { USP; } \\
\text { USP. }\end{array}$ \\
\hline 9 & $\begin{array}{l}\text { Os manuais de ensino de Geografia produzidos no } \\
\text { primeiro terço do século XX: fontes e objetos de } \\
\text { estudo }\end{array}$ & $\begin{array}{l}\text { Márcia Cristina de } \\
\text { Oliveira Mello }\end{array}$ & UNESP \\
\hline 10 & $\begin{array}{l}\text { Os países tropicais nos livros didáticos de } \\
\text { Geografia do ensino secundário francês entre } 1925 \\
\text { e } 1960\end{array}$ & Hervé Thery & USP \\
\hline 11 & $\begin{array}{l}\text { As temáticas físico-naturais nos livros didáticos e } \\
\text { no ensino de Geografia }\end{array}$ & $\begin{array}{l}\text { Eliana Marta Barbosa } \\
\text { de Morais }\end{array}$ & $\begin{array}{l}\text { UFG (Universidade } \\
\text { Federal de Goiás) } \\
\end{array}$ \\
\hline 12 & $\begin{array}{l}\text { Presença indígena nos livros didáticos de } \\
\text { Geografia }\end{array}$ & Rafaela Biehl Printes & $\begin{array}{c}\text { UERGS (Universidade } \\
\text { Estadual do Rio Grande do } \\
\text { Sul) }\end{array}$ \\
\hline 13 & $\begin{array}{l}\text { Regimes visuais da questão ambiental nos livros } \\
\text { didáticos de Geografia na Argentina }\end{array}$ & Verónica Hollman & $\begin{array}{l}\text { UBA (Universidade de } \\
\text { Buenos Aires) }\end{array}$ \\
\hline
\end{tabular}

Fonte: Organização dos autores.

Revista Cerrados, Montes Claros/MG, v.17, n. 2, p. 47-65, jul./dez.-2019. 
MELLO, B. F.; PEZZATO, J. P.

Uma leitura do dossiê da Revista Brasileira de Educação em Geografia (2014): ora compêndios, ora livros escolares, ora livros didáticos

Gráfico 1 - Número de autores por instituições de ensino superior (nacionais e internacionais)

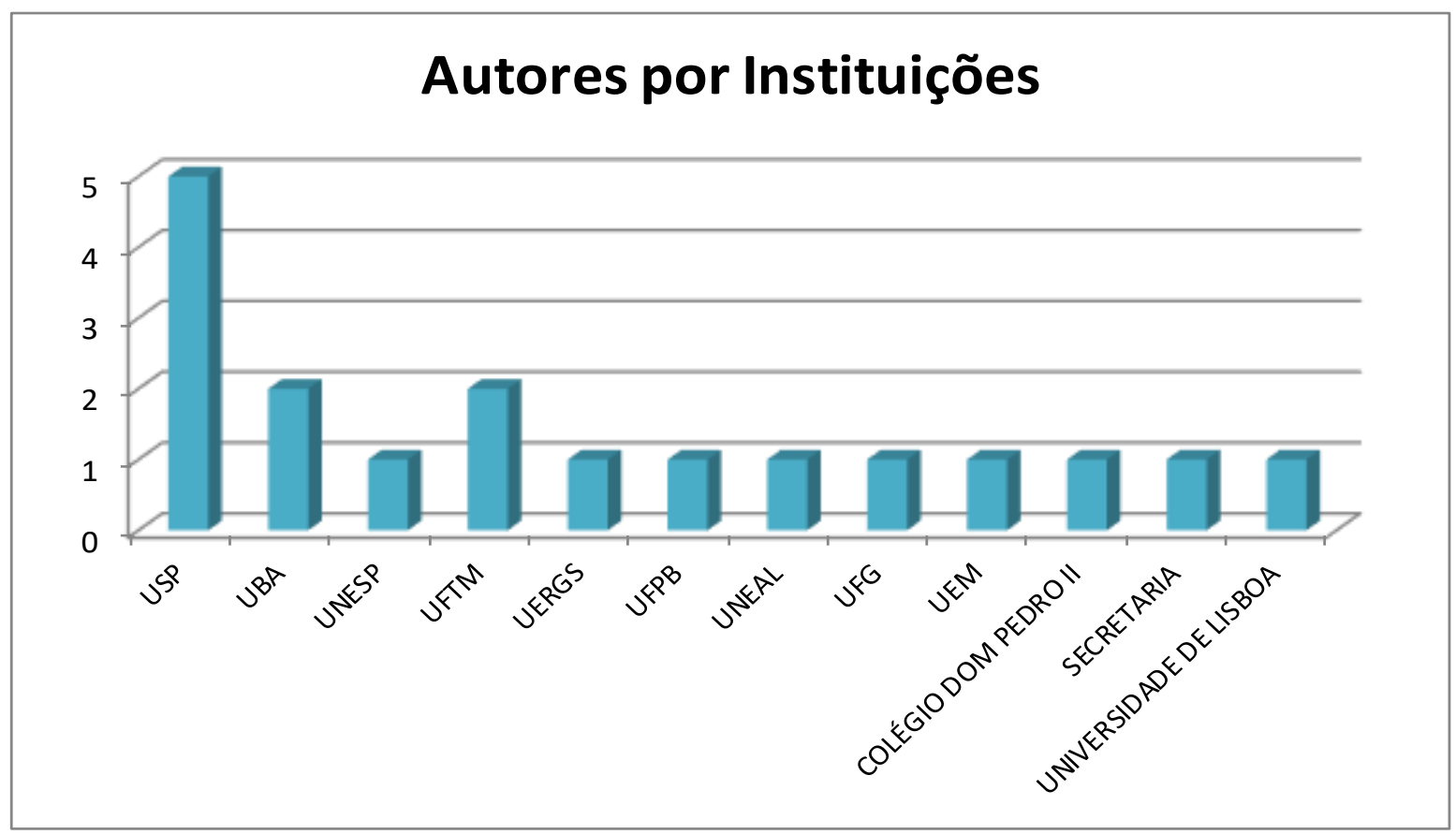

Fonte: Organização dos autores.

Das instituições nacionais, duas delas estão localizadas, e concentrando o maior número de autores, no estado de São Paulo. As outras instituições estão distribuídas entre os estados de Minas Gerais, Paraíba, Rio Grande do Sul, Paraná, Alagoas e Goiás. A partir dessa quantificação, um mapa de espacialização foi elaborado (Figura 1).

Em segundo momento de análise, foi realizada a leitura individual de cada artigo. Nota-se que os artigos, a despeito de estarem ligados ao mesmo tema - o estudo dos livros didáticos de Geografia - apresentam variações quanto à abordagem. A partir da leitura foi possível identificar e estabelecer, para fins de melhor apuração, três categorias ligadas ao período histórico de análise do material (livros didáticos, de texto, para crianças, escolares, manuais escolares, textos didáticos, entre outros) envolvidos em cada artigo.

Para o estabelecimento dessas categorias foram escolhidos, como já comentado, os períodos da história nacional. Fez-se a escolha em razão de os próprios artigos se acharem divididos também por diferentes períodos da história. Os três períodos escolhidos são o colonial, o imperial e o republicano. Optou-se por desconsiderar o primeiro artigo, pois esse é, na verdade, uma introdução ao tema e breve apresentação dos demais. 
MELLO, B. F.; PEZZATO, J. P.

Uma leitura do dossiê da Revista Brasileira de Educação em Geografia (2014): ora compêndios, ora livros escolares, ora livros didáticos

Figura 1 - Espacialização das instituições a que pertencem os autores pesquisados

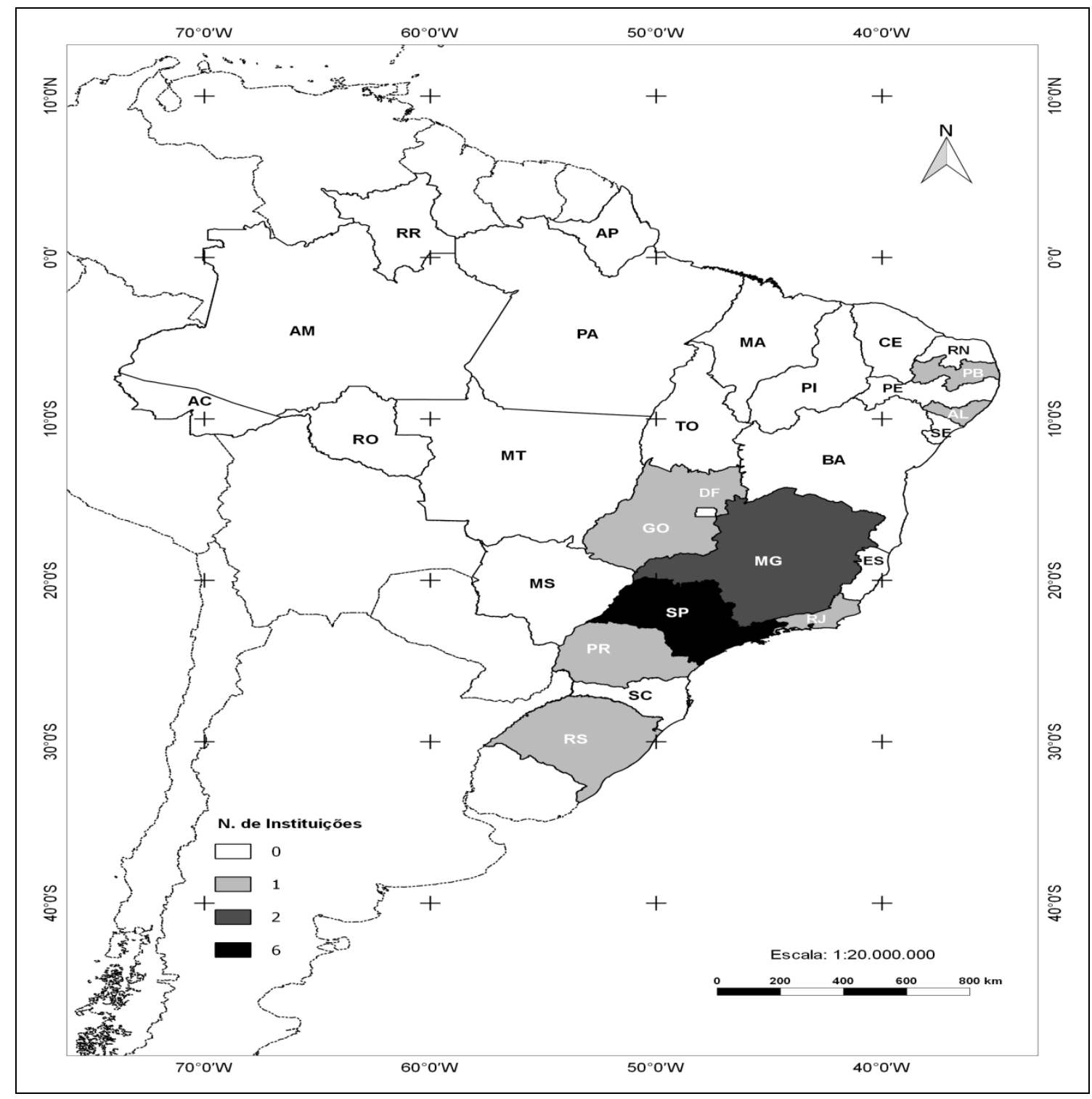

Fonte: Organização dos autores.

\section{Período Pós-Colonial (1 artigo):}

Para a primeira categoria de análise, há somente um artigo referente a materiais desse período. $\mathrm{O}$ artigo de Claudino traz a análise de um manual escolar português lançado quatro anos após a independência do Brasil, em 1926, de autoria de Joaquim Pedro Cardoso Casado Girales, intitulado Compêndio de Geografia Histórica Antiga e Moderna e 
MELLO, B. F.; PEZZATO, J. P.

Uma leitura do dossiê da Revista Brasileira de Educação em Geografia (2014): ora compêndios, ora livros escolares, ora livros didáticos

Cronologia, para uso da Mocidade Portuguesa. O autor nutre expectativas quanto a uma possível (re)união entre os dois países por meio de Dom Pedro I. O Brasil é retratado de forma bastante positiva, apesar da dificuldade inicial dos portugueses em aceitar a independência.

Considerando os manuais escolares como instrumentos de poder, o autor Casado Girales reflete em sua obra os valores liberais de Portugal no primeiro quartel do século XIX, bem com as ideologias e os interesses institucionais e políticos de país naquele momento, sobretudo o que tocava à sua principal e próspera ex-colônia.

\section{Período Imperial a partir de 1822 até 1910 ( 1 artigo):}

Nesta categoria somente um artigo fez referência a materiais desse período da história brasileira. A análise é feita sobre o artigo de Ângelo e Albuquerque, o qual põe em evidência a importância dos autores dos livros didáticos como sujeitos sociais e como construtores da disciplina escolar de Geografia em um período transitório das províncias para os estados, com destaque na pós-proclamação da República.

As autoras dão destaque ao Ato Institucional de agosto de 1834, por meio do qual a administração pública passa a escolarização primária e secundária aos governos locais, o que, ao entender delas, acaba por levar a uma fragmentação do ensino pensado no período anterior: este não é mais articulado com o governo central.

A maior parte das publicações desse período tinha caráter regionalista. Geralmente eram impressas nos próprios locais onde seriam utilizadas. As autoras constataram que as publicações regionais para o ensino primário eram mais numerosas que as do ensino secundário, o que denota ênfase naquela modalidade de ensino.

Outro ponto digno de nota são algumas características comuns a alguns autores: possuem mais de uma formação, sendo atuantes em diferentes atividades e setores da sociedade, e parte deles estando ligados a funções políticas ou tendo relações próximas com o poder provincial. Essas características são referentes aos casos de dois autores citados, a saber, o paraense Carlos Augusto Valente de Novaes e o baiano Jerônimo Sodré Pereira, que tem forte ligação com seus "lugares sociais". 
MELLO, B. F.; PEZZATO, J. P.

Uma leitura do dossiê da Revista Brasileira de Educação em Geografia (2014): ora compêndios, ora livros escolares, ora livros didáticos

\section{Período Republicano a partir de 1889 (8 artigos):}

Nesta categoria de análise, que inclui o período de pós-proclamação da República, foram incluídos 8 artigos, nos quais se encontram algumas divisões também ligadas a diferentes períodos.

Para a primeira análise desta categoria está Azambuja, que em seu artigo compreende três períodos: do começo do século XX até a década de 1960; a seguir, pelas mudanças ocorridas com a implementação da Lei 5692/71 ( $1^{\circ}$ grau de 8 anos e $2^{\circ}$ grau de 3 anos); por último, a Lei de Diretrizes e Bases da Educação Nacional de nº 9.394/96 (Ensino Fundamental de 9 anos e Ensino Médio de 3 anos). No primeiro momento de análise o autor destaca dois nomes, Delgado de Carvalho e Aroldo de Azevedo. No segundo, comenta sobre a implementação dos Estudos Sociais no $1^{\circ}$ grau, além de um significativo aumento no número de editoras, títulos e autores dos livros didáticos. Despontam os autores Melhem Adas e Igor Moreira, que se destacam por suas produções didáticas voltadas ao $1^{\circ}$ grau. Para o $2^{\circ}$ grau surge o nome de José Wiliam Vesentini, entre outros. No último período, destaca as análises de textos oficiais de orientação ou ainda parâmetros curriculares que norteiam os conteúdos e formas, válidos nacionalmente, para os agora níveis de ensino fundamental e médio.

O artigo das autoras Silva, Gallego e Vicentini trata justamente da questão de como os livros didáticos se constituem, desde o século XIX, em diversas partes do mundo, em parte do projeto dos Estados-nação. Em sua análise, cuja periodização compreende o período de 1870 a 1970 e abrange a produção brasileira e portuguesa de livros didáticos para a Escola Normal, elas se indagam se os autores desses materiais seriam originais em sua escrita ou tão somente compiladores das ideias de outros escritores. Para elas, no entanto, autor não é aquele que apenas escreve um texto, mas quem o faz imprimir, circular e reverberar suas ideias. Em suma, autor é fundador de discursividade.

Outros dois artigos apresentam uma análise de conteúdos de caráter mais específico, como o caso do artigo de Pereira e Gonçalves sobre os manuais da professora Hermantina Ricciopo em Minas Gerais na década de 1960 e o artigo de Silva com a produção do saber escolar na região Nordeste na primeira metade do século XX. Na obra de Riccioppo notam-se pressupostos escolanovistas e uma grande preocupação com a práxis, isso é, 
MELLO, B. F.; PEZZATO, J. P.

Uma leitura do dossiê da Revista Brasileira de Educação em Geografia (2014): ora compêndios, ora livros escolares, ora livros didáticos

preocupação com uma formação sociocultural mínima à classe trabalhadora e aproximação dos temas de Geografia escolar ao cotidiano dos alunos, cuja escala começa no bairro.

Silva, por sua vez, buscou observar se a materialização do tema Nordeste feito nos livros didáticos obedecia à realidade. A autora conclui que a descrição da região se tornou algo homogêneo, tanto para os aspectos físicos, descrições e análises, principalmente do Ceará. Quanto aos aspectos humanos, o mesmo se aplica: a descrição do cearense tornou-se a descrição dos nordestinos, criando estereótipos.

O artigo de Oliveira Mello guarda semelhanças como de Azambuja, pois analisa manuais de ensino de Geografia produzidos nos primeiros trinta anos do século XX. Segundo a autora, a orientação da Geografia moderna e os preceitos dos métodos modernos da pedagogia científica guiaram a produção dos novos currículos escolares, sob os preceitos da Escola Nova. Três obras particulares refletem a nova tendência pedagógica: Methodologia do ensino geográfico: introdução aos estudos de Geografia Moderna, de Delgado de Carvalho, publicado em 1925; Como se ensina Geografia, de Firmino de Proença, publicado em 1928; Didáctica: nas escolas primárias, de João Toledo, publicado em 1930.

A concepção de aluno no escolanovismo tinha em vista promover o desenvolvimento natural do educando. Para seus adeptos, o importante não é aprender coisas, mas aprender a observar, a pesquisar, a pensar, aprender a aprender. Esses princípios se refletem nas obras dos três autores citados. A metodologia de Delgado de Carvalho considerava a necessidade de o ensino de Geografia objetivar que o aluno construísse uma determinada imagem do território nacional, com destaque às diferenças de cada região. Região natural foi a categoria de análise por ele empregada.

As temáticas físico-naturais nos livros didáticos e no ensino de Geografia foram objeto de análise de Moraes. A autora realizou entrevistas com 60 docentes da rede municipal e estadual da cidade de Goiânia, estado de Goiás, bem como analisou todos os livros didáticos aprovados pelo Plano Nacional do Livro Didático do ano de 2008 voltados ao sexto ano do ensino fundamental.

Suas conclusões apontam não haver homogeneização dos temas relevo, rochas e solo: constatou-se que alguns livros didáticos tratam dos três temas, outros de apenas dois e outros ainda de apenas um. Os temas são tratados de forma descontextualizada; é dada a preferência ao relevo, em primeiro lugar, seguido de rochas e solos. A referência básica de 
MELLO, B. F.; PEZZATO, J. P.

Uma leitura do dossiê da Revista Brasileira de Educação em Geografia (2014): ora compêndios, ora livros escolares, ora livros didáticos

Geografia física nos livros consultados é o relevo. Surpreendentemente, as questões sociais são tratadas em segundo plano e de forma abstrata quando os conteúdos de relevo, rocha e solo são abordados: não há efetiva vinculação destes com aquelas.

Antes de prosseguir com as análises das categorias, um ponto merece destaque nos artigos de modo geral. Tal ponto pareceu ser abordado nos artigos de forma frequente e refere-se à questão da reafirmação do caráter nacional por meio dos livros didáticos. Essa afirmação, do mesmo modo como coloca Choppin (2004), serve também para formação do caráter de cidadão, já que nos anos após a proclamação da República o sentimento e a identificação com o nacional estavam sendo gestados.

Tanto a educação, de forma geral, quanto os livros didáticos escolares tornaram-se veículos do Estado para a formação de um espírito nacional. A disseminação do ideal nacionalista para criação de uma identidade coletiva foi feita por meio da língua, da cultura, da história e nos livros de Geografia, principalmente com o território por repetições e descrições de forma a serem memorizadas.

A forma de produção dos materiais, mesmo após a recém-constituição dos Estados Nacionais (século XIX), como colocado por Choppin, possuíam certas características ainda influenciadas por modelos de ensino europeu:

As antigas colônias, notadamente na América Latina, [...] que se abrem à influência ocidental, vão adotar modelos educativos europeus ou neles se inspirar fortemente e colocar rapidamente em prática regulamentações específicas para controlar a elaboração, a produção, a distribuição e o uso das obras de cunho didático (CHOPPIN, p. 555, 2004).

A autora Carolina Lima Vilela apresenta os livros didáticos como importantes elementos da cultura escolar, que possuem discursos ligados ao conhecimento de Geografia. Os discursos se referem à abordagem regional, ligada por sua vez ao caráter descritivo e enciclopédico característico da Geografia tradicional. Esse caráter se tornou uma prática recorrente nos livros, mesclando assim a Geografia "alienada" ou "tradicional" com a Geografia crítica e formando conteúdos ditos “inovadores”, que estão presentes nos currículos atuais.

A autora aborda o conceito de região, de forte presença nos livros didáticos, não como categoria de estudos geográficos, mas sim como uma diferenciação de áreas mais homogêneas. Com base nessas regiões, ou regionalizações, os capítulos e conteúdos dos 
MELLO, B. F.; PEZZATO, J. P.

Uma leitura do dossiê da Revista Brasileira de Educação em Geografia (2014): ora compêndios, ora livros escolares, ora livros didáticos

materiais são organizados, principalmente como forma de integração entre os fenômenos humanos e naturais, trazendo à Geografia o caráter integrador dos fenômenos naturais e sociais, atribuindo a ela a regularidade do discurso.

O último artigo do período nacional aborda a presença indígena nos livros didáticos de Geografia, a qual foi alvo do estudo de Printes. Focando-se em livros didáticos do sexto e sétimo ano do ensino fundamental dos anos de 2008 e de 2014, a autora buscou compreender como se tem dado a abordagem da temática e o contexto em que ela é feita. Principia seu artigo tecendo considerações acerca da importância dos livros didáticos enquanto máquinas de produção de sentidos. A seguir, traça um panorama do tratamento dispensado aos indígenas em livros didáticos desde os anos 1980, quando os índios eram apresentados aos alunos de maneira superficial e caricata: índio faz canoa, anda nu, gosta de se enfeitar e comer mandioca.

Os enfoques da questão indígena variam nos livros didáticos consultados: ora dão pouco destaque e retratam os índios de maneira anódina, como é o caso das obras Geovida olhar geográfico (2008) e Projeto Araribá (2014), sem se preocupar com a questão da posse da terra, ora os tratam com mais complacência e visão crítica, incluindo questões de posse de terra, desmatamento e migração para áreas urbanas, como é caso dos livros de Melhem Adas. Os índios são, via de regra, vinculados à Região Norte do país. Aqueles que se valem de alguma tecnologia moderna, como máquinas fotográficas e telefones celulares, são retratados como tendo perdido a identidade indígena.

\section{Artigos de outras nacionalidades}

Os artigos ligados a outras nacionalidades são sobre a França e Argentina. O autor Hervé Thery procede à análise dos países tropicais nos livros didáticos franceses voltados ao ensino secundário entre 1925 e 1960. Inicialmente descritiva e inventariante, a Geografia passa gradativamente à explicação dos fenômenos. Reconhecidos geógrafos acadêmicos, como Pierre Gourou, encarregam-se da produção de alguns materiais didáticos.

Os manuais obedecem a oito sucessivas diretrizes curriculares: 1925, 1931, 1937, 1938, 1941, 1943, 1944 e 1945, havendo, ainda, um nono em 1960. O currículo de 1925 é uma repetição do currículo de 1902, que por sua vez remonta ao do ministro da educação 
MELLO, B. F.; PEZZATO, J. P.

Uma leitura do dossiê da Revista Brasileira de Educação em Geografia (2014): ora compêndios, ora livros escolares, ora livros didáticos

Jules Ferry, quando da instituição do ensino público, gratuito e laico na França. Os conteúdos partem da análise geral para a particular, ou seja, do mundo para a França via Europa. Os currículos que sucedem o de 1925 seguem essa tendência. Grande atenção é dada ao continente africano, onde foi realizada a maior parte do esforço colonial francês.

A África é vista de forma negativa, como um continente fechado e pouco acolhedor. A imagem que a maior parte dos autores quer passar aos alunos é a de uma França detentora de um império de colônias de exploração. Notadamente, a visão sobre os nativos é preconceituosa e de cunho racista. A fim de justificar a exploração colonial na África, a França se outorgou o papel de difusora da civilização ocidental e portadora do savoir-faire necessário para o desenvolvimento do continente.

$\mathrm{O}$ artigo de Verónica Hollman trata sobre os regimes visuais da questão ambiental em livros didáticos de Geografia da Argentina. A despeito da internet e de todas as tecnologias hoje disponíveis, o livro didático ainda ocupa lugar central no sistema educacional argentino. A imagem deixa sua tradicional função ilustrativa para se tornar uma portadora de conteúdos.

Para a autora, uma imagem torna-se efetiva para apresentar um problema ambiental quando reedita algumas chaves visuais que, pela sua recorrente aparição em outros registros discursivos, ativam nossa memória ambiental. A primeira chave é utilizar imagens que já se tornaram ícones ambientais, como, por exemplo, a imagem de um urso panda. Outra chave consiste em apresentar imagens aéreas. A última chave é a apelação a imagens ou composição de imagens que permitem introduzir a variável temporal, ou seja, mostrar a mudança de algum evento com consequências ambientais, valendo-se de imagens do mesmo lugar em dois momentos ou mais.

\section{RESULTADOS}

Realizada a análise dos artigos do dossiê, passou-se à resposta às perguntas formuladas inicialmente: Quais motivos levaram à publicação de um dossiê sobre o tema de livros didáticos na história da disciplina na Revista Brasileira de Ensino em Geografia no ano de 2014? Tais produções estão, de alguma forma, ligadas com a realidade escolar nacional? 
MELLO, B. F.; PEZZATO, J. P.

Uma leitura do dossiê da Revista Brasileira de Educação em Geografia (2014): ora compêndios, ora livros escolares, ora livros didáticos

As análises estabelecem relações com a história do pensamento geográfico e sua epistemologia?

Sobre os motivos para publicação de um dossiê contendo treze artigos sobre livros didáticos, pensamos que há duas razões: 1) é um tema amplo e relativamente pouco explorado, 2) a área de estudos de livros didáticos de Geografia precisa ser mais desenvolvida, pois está intrinsecamente ligada à história da Geografia como parte da cultura escolar. Como o título do dossiê sugere, ora essas obras levam uma nomenclatura, ora outra. A despeito disso, continuam sendo de fundamental importância e o principal apoio do docente de Geografia, uma vez que portam os princípios básicos da disciplina. Obviamente, não se pode esquecer que cada obra carrega consigo uma significativa carga ideológica, como tratam os artigos de Hervé Thery, Sérgio Claudino e Rafaela Biehl Printes.

As produções veiculadas no dossiê estão intimamente ligadas à realidade escolar nacional, quando se trata de Brasil. Os autores não se esquivaram das pertinentes críticas aos manuais examinados, mas também não deixaram de reconhecer sua importância dentro da época em que circularam.

O estabelecimento de conexões com a história do pensamento geográfico e com a epistemologia pode ser notada nos artigos, mas de maneira e intensidade diferente cada qual. A principal convergência é quanto ao conceito de região, que é trabalhada em praticamente todos os livros didáticos consultados. Alguns dos autores de artigos aprofundam-me mais no tema, remontando às obras clássicas da Geografia e aos principais conceitos da disciplina, como região natural, mostrando como esses foram trabalhados nos livros didáticos consultados. A esse respeito, o artigo de Leonardo Dirceu de Azambuja traça paralelos entre os conteúdos dos livros didáticos de Delgado de Carvalho e Aroldo de Azevedo, vinculados aos postulados clássicos da Geografia, e os conteúdos dos livros dos anos 1980 e 1990, de autores como José Willian Vesentini e Melhem Adas, que repercutem em suas obras as novas tendências da disciplina.

Cabe destacar, por derradeiro, a análise das bases referenciais, utilizadas para elaboração dos artigos por cada autor. Tais bases foram sistematizadas no Quadro 2: 
MELLO, B. F.; PEZZATO, J. P.

Uma leitura do dossiê da Revista Brasileira de Educação em Geografia (2014): ora compêndios, ora livros escolares, ora livros didáticos

Quadro 2 - Número de autores e números de vezes em que foram citados.

\begin{tabular}{|l|c|}
\hline \multicolumn{1}{|c|}{ Autores citados nas referências (como primeiro autor) } & $\begin{array}{c}\text { Número de vezes que são } \\
\text { indicados }\end{array}$ \\
\hline Autores (diversos) indicados uma vez & 180 \\
\hline Autores indicados duas vezes (em 1 ou 2 artigos) & 25 \\
\hline $\begin{array}{l}\text { Autores indicados três vezes (CHARTIER, R; } \\
\text { ALBUQUERQUE, M.A.M. de; CLAUDINO, S.; } \\
\text { PONTUSCHKA, N. N.) }\end{array}$ & 4 \\
\hline Autores indicados quatro vezes (CHOPPIN, A.; CHERVEL, A.) & 2 \\
\hline $\begin{array}{l}\text { Publicações oficiais } \\
\text { (Brasil - 4; SÃO PAULO -1; FUNAI -1; ) }\end{array}$ & 6 \\
\hline Não creditado ( Total & 46 \\
\hline \multicolumn{2}{c}{ Tra } \\
\hline
\end{tabular}

Fonte: Organização dos autores.

1. Dos autores referenciados nos 13 artigos, estes são citados: 180 deles uma única vez; 25 citados duas vezes, então ao todo $50 ; 3$ deles referenciados quatro vezes, então $12 ; 4$ referenciados duas vezes, então $8 ; 4$ publicações oficiais; 46 não creditados. Total de 302.

\section{CONSIDERAÇÕES FINAIS}

A análise dos livros didáticos ao longo de uma série temporal, ora chamados de manuais, ora chamados de compêndios, revela-se importante fonte de pesquisa e reflexão ao pesquisador que deseja desvendar toda a sorte de trama ideológica, política e pedagógica que lhes deram aporte.

Neste artigo, dedicado à compreensão do dossiê da Revista Brasileira de Educação em Geografia vol. 4, n. 8, de 2014, ficou claro que os livros didáticos de Geografia são de inegável e fundamental importância para o estudo da história das disciplinas escolares e, também, para o aprofundamento do conhecimento a respeito do ensino da disciplina, não apenas no Brasil, mas também em outros países. Não se pode deles abrir mão em sala de aula, haja vista se constituírem em ferramentas de excepcional alcance social - atingem todas as classes - e de aculturação de massa enquanto parte das atividades concernentes à cultura escolar, conforme assevera Chervel (1988, p. 70).

Apesar da distância temporal de algumas obras analisadas, não se pode deixar de registrar também a relevância da Geografia escolar no papel promocional dos Estados nacionais. Os artigos de Ângelo e Albuquerque e de Silva, Gallego e Vicentini, por exemplo, ilustram bem a forma como os Estados souberam se valer da Geografia e dos livros didáticos 
MELLO, B. F.; PEZZATO, J. P.

Uma leitura do dossiê da Revista Brasileira de Educação em Geografia (2014): ora compêndios, ora livros escolares, ora livros didáticos

para difundir os ideais que gostariam que fossem assimilados pelos educandos. No caso brasileiro, vê-se tanto no Império quanto na República o esforço despendido a fim de bem cumprir esse objetivo.

Da mesma forma, nos artigos do dossiê apreciado fez-se notório o rigor metodológico seguido por significativo número de autores e a preocupação com a citação de fontes representativas, de forma a aquilatar seus trabalhos. As comparações feitas entre pensadores acadêmicos, autores de livros didáticos e as diversas edições por eles produzidas, em épocas distintas, trazem a lume intenções que somente um olhar acurado consegue se aperceber: os discursos ocultos por trás das obras (quer sejam liberais, monarquistas ou republicanos) e as linhas teóricas seguidas pelos autores desses livros, tanto no âmbito da ciência de referência (Geografia tradicional de cunho positivista, neopositivista, Geografia crítica, humanística) quanto no que se refere às orientações de cunho didático. No caso das perspectivas pedagógicas, elas são mais insinuadas que explicitadas, apontando abordagens de perspectiva construtivista-interacionista, ou com aproximações de caráter sociocultural, ora com maiores nuances conteudista, ora existencialista, ora revolucionária. Nas análises dos livros didáticos dos autores do dossiê, é possível observar, em alguns trechos, o reforço de determinados estereótipos (índio como bom selvagem, africano como atrasado etc.).

Outro ponto digno de nota é que o tema livros didáticos está presente em diversos programas de pós-graduação do país. A nosso entender, a diversidade de instituições que se debruçam sobre a matéria denota a relevância que esses livros têm no contexto escolar e, se assim nos for permitida a colocação, até mesmo o papel de promoção civilizadora que se lhes pode atribuir.

Contemplando cada qual uma temática e uma determinada época, os artigos traçam, destarte, um panorama da Geografia escolar enquanto disciplina que permanece historicamente nos currículos da educação brasileira e de outros países. Os organizadores do dossiê tiveram o cuidado de apresentar ao debate acadêmico artigos que propõem reflexões oportunas sobre autores e seus livros didáticos. É um tema que não se esgota e se renova a cada época; está sempre em transformação, como o próprio pensamento humano.

\section{AGRADECIMENTOS}

Os autores agradecem a colaboração da acadêmica Lilian Dias Evangelista. 
MELLO, B. F.; PEZZATO, J. P.

Uma leitura do dossiê da Revista Brasileira de Educação em Geografia (2014): ora compêndios, ora livros escolares, ora livros didáticos

\section{REFERÊNCIAS}

ANGElO, Maria Deusia Lima; ALBUQUERQUE, Maria Adailza Martins de. Autores e livros didáticos regionais de Geografia (1870-1910): elementos históricos e educacionais para uma espacialização do fenômeno. Revista Brasileira de Educação em Geografia. Campinas, v. 4, n. 8, p. 88-112, jul./dez. 2014. Disponível em:

<http://www.revistaedugeo.com.br/ojs/index.php/revistaedugeo/article/view/241>. Acesso em: 01 de setembro de 2016.

AZAMBUJA, Leonardo Dirceu. O livro didático e o ensino de Geografia. Revista Brasileira de Educação em Geografia. Campinas, v. 4, n. 8, p. 11-33, jul./dez. 2014. Disponível em: < http://www.revistaedugeo.com.br/ojs/index.php/revistaedugeo/article/view/180>. Acesso em: 01 de setembro de 2016.

CHERVEL, André. L'histoire des disciplines scolaires. Réflexions sur un domaine de recherche. Histoire de l'éducation, n. 38, p. 59-119, 1988. Disponível em: <http://www.persee.fr/web/revues/home/prescript/article/hedu_02216280_1988_num_38_1_1593>. Acesso em: 01 de setembro de 2016.

CHOPPIN, Alain. História dos livros e das edições didáticas: sobre o estado da arte. Educação e Pesquisa. São Paulo, v. 30, n.3, p. 549-566, set./dez., 2004. Disponível em: http://www.scielo.br/pdf/ep/v30n3/a12v30n3.pdf>. Acesso em: 01 de setembro de 2016.

CLAUDINO, Sérgio. O Brasil é independente? Geografia e ideologia no primeiro manual escolar do liberalismo português. Revista Brasileira de Educação em Geografia. Campinas, v. 4, n. 8, p. 113-129, jul./dez. 2014. Disponível em: <

http://www.revistaedugeo.com.br/ojs/index.php/revistaedugeo/article/view/242>. Acesso em: 01 de setembro de 2016.

FERRACINI, Rosemberg; HOLLMAN, Verónica. Ora compêndios, ora livros escolares, ora livros didáticos... sempre necessários na Geografia escolar. Revista Brasileira de Educação em Geografia. Campinas, v. 4, n. 8, p. 03-10, jul./dez. 2014. Disponível em: < http://www.revistaedugeo.com.br/ojs/index.php/revistaedugeo/article/view/183>. Acesso em: 01 de setembro de 2016.

HOLLMAN, Verónica. Regimes visuais da questão ambiental nos livros didáticos de Geografia na Argentina. Revista Brasileira de Educação em Geografia. Campinas, v. 4, n. 8, p. 221-240, jul./dez. 2014. Disponível em: <

http://www.revistaedugeo.com.br/ojs/index.php/revistaedugeo/article/view/248>. Acesso em: 01 de setembro de 2016.

MELLO, Márcia Cristina de Oliveira. Os manuais de ensino de Geografia produzidos no primeiro terço do século XX: fontes e objetos de estudo. Revista Brasileira de Educação em Geografia. Campinas, v. 4, n. 8, p. 146-159, jul./dez. 2014. Disponível em: < http://www.revistaedugeo.com.br/ojs/index.php/revistaedugeo/article/view/244>. Acesso em: 01 de setembro de 2016. 
MELLO, B. F.; PEZZATO, J. P.

Uma leitura do dossiê da Revista Brasileira de Educação em Geografia (2014): ora compêndios, ora livros escolares, ora livros didáticos

MORAIS, Eliana Marta Barbosa de. As temáticas físico-naturais nos livros didáticos e no ensino de Geografia. Revista Brasileira de Educação em Geografia. Campinas, v. 4, n. 8, p. 175-194, jul./dez. 2014. Disponível em: < http://www.revistaedugeo.com.br/ojs/index.php/revistaedugeo/article/view/246>. Acesso em: 01 de setembro de 2016.

PEREIRA, Diego Carlos; GONÇALVES, Amanda Regina. Os manuais escolares de Hermantina Riccioppo: resgates da produção de conhecimento geográfico escolar no Triângulo Mineiro, em meados do século XX. Revista Brasileira de Educação em Geografia. Campinas, v. 4, n. 8, p. 34-54, jul./dez. 2014. Disponível em:

$<$ http://www.revistaedugeo.com.br/ojs/index.php/revistaedugeo/article/view/238>. Acesso em: 01 de setembro de 2016.

PRINTES, Rafael Biehl. Presença indígena nos livros didáticos de Geografia. Revista Brasileira de Educação em Geografia. Campinas, v. 4, n. 8, p. 195-220, jul./dez. 2014. Disponível em:

< http://www.revistaedugeo.com.br/ojs/index.php/revistaedugeo/article/view/247>. Acesso em: 01 de setembro de 2016.

SILVA, Maria Ediney Ferreira. A produção e circulação do saber escolar: o Nordeste enquanto conteúdo escolar nos livros didáticos de Geografia. Revista Brasileira de Educação em Geografia. Campinas, v. 4, n. 8, p. 71-87, jul./dez. 2014. Disponível em: < http://www.revistaedugeo.com.br/ojs/index.php/revistaedugeo/article/view/240>. Acesso em: 01 de setembro de 2016.

SILVA, Vivian Batista; GALLEGO, Rita de Cássia; VICENTINI, Paula Perin. Aprendendo a ensinar através dos livros: notas sobre a natureza e a produção dos manuais para professores (Brasil e Portugal - 1870-1970). Revista Brasileira de Educação em Geografia. Campinas, v. 4, n. 8, p. 130-145, jul./dez. 2014. Disponível em: <

http://www.revistaedugeo.com.br/ojs/index.php/revistaedugeo/article/view/243>. Acesso em: 01 de setembro de 2016.

THERY, Hervé. Os países tropicais nos livros didáticos de Geografia do ensino secundário francês entre 1925 e 1960. Revista Brasileira de Educação em Geografia. Campinas, v. 4, n. 8, p. 160-174, jul./dez. 2014.

Disponível em: <

http://www.revistaedugeo.com.br/ojs/index.php/revistaedugeo/article/view/245>. Acesso em: 01 de setembro de 2016.

VILELA, Carolina Lima. Livros didáticos e o discurso do conhecimento escolar em Geografia: a abordagem regional como regularidade. Revista Brasileira de Educação em Geografia. Campinas, v. 4, n. 8, p. 55-70, jul./dez. 2014. Disponível em: <

http://www.revistaedugeo.com.br/ojs/index.php/revistaedugeo/article/view/239>. Acesso em: 01 de setembro de 2016. 
MELLO, B. F.; PEZZATO, J. P.

Uma leitura do dossiê da Revista Brasileira de Educação em Geografia (2014): ora compêndios, ora livros escolares, ora livros didáticos

\section{Autores}

Bruno Falararo de Mello - Possui Graduação e Mestrado em Geografia pela Universidade Estadual Paulista Júlio de Mesquita Filho (UNESP/Rio Claro). Atualmente é Doutorando do Programa de Pós-Graduação em Geografia da Universidade Estadual Paulista Júlio de Mesquita Filho (UNESP/Rio Claro).

João Pedro Pezzato - Possui Graduação em Geografia pela Universidade Estadual Paulista Júlio de Mesquita Filho (UNESP/Rio Claro), Mestrado e Doutorado em Educação pela Universidade de São Paulo (USP). Atualmente é professor do Programa de Pós-Graduação em Geografia da Universidade Estadual Paulista Júlio de Mesquita Filho (UNESP/Rio Claro).

Artigo recebido em: 31 de janeiro de 2019.

Artigo aceito em: 15 de julho de 2019.

Artigo publicado em: 29 de julho de 2019. 